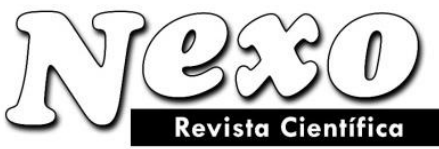

Vol. 34, No. 05 (Especial), pp. 20-29/Diciembre 2021
ISSN-E 1995-9516

Universidad Nacional de Ingeniería COPYRIGHT () (UNI). TODOS LOS DERECHOS RESERVADOS http://revistas.uni.edu.ni/index.php/Nexo https://doi.org/10.5377/nexo.v34i05.13100

\title{
Prácticas urbanas, obreras y culturales en San Cristóbal inicios siglo XX - Suroriente de Bogotá, Colombia
}

Urban, working-class and cultural practices in San Cristóbal in the early twentieth century

- Southeast of Bogotá, Colombia

\author{
Liliana Cortés Garzón \\ Directora Proyecto Sur
}

$\underline{\text { lcortesgarzon@gmail.com }}$

(recibido/received: 16-septiembre-2021; aceptado/accepted: 28-noviembre-2021)

\section{RESUMEN}

Esta investigación aborda la relación entre las prácticas obreras y culturales en San Cristóbal, el suroriente de la ciudad de Bogotá a inicios del siglo XX. La investigación y metodología abordan archivos fotográficos que, como fuentes primarias, relatan una urbanización en relación con las culturas locales, prácticas obreras y artesanales, que configuran una población asentada hace cerca de un siglo con regulaciones sociales que impactaron sus prácticas culturales y movilidad urbana y que construye una forma comunitaria de interacción social.

Palabras claves: Obreros, industrias, urbanización, San Cristóbal.

\section{ABSTRACT}

This research addresses the relationship between worker and cultural practices in San Cristóbal, the southeast of the city of Bogota at the beginning of the 20th century. The research and methodology address photographic archives that, as primary sources, relate an urbanization in relation to local cultures, worker and artisan practices, which make up a population settled nearly a century ago with social regulations that impacted their cultural practices and urban mobility and that builds a communal form of social interaction.

Keywords: Workers, industries, urbanization, San Cristóbal.

\section{INTRODUCCIÓN}

Las formas de trabajo de carácter obrero en la Localidad cuarta de San Cristóbal en el suroriente de la ciudad de Bogotá, están íntimamente relacionadas a la producción artesanal de oficios tradicionales, prácticas culturales y urbanas que evidencian una herencia cultural regional de diversos lugares de Colombia, dadas por la migración generada por las violencias regionales, pero al mismo tiempo, con formas de producción cultural urbana informal en el uso del espacio público como un lugar de habitación de grupos poblacionales que si bien reproducen violencias locales, 
también formas festivas culturales en las cuales se producen prácticas culturales que evidencian memorias en relación a paisajes rurales o prácticas festivas y de religiosidad popular.

Prácticas culturales, las comparsas, danzas, músicas locales, reinterpretan el trabajo obrero, los oficios y los saberes desde sus celebraciones populares y fiestas que, si bien tienen rasgos católicos frente al culto del Divino niño, culto establecido a inicios del siglo XX por el Padre salesiano Juan del Rizzo en 1935 en el Barrio 20 de Julio, se extendió por toda la ciudad de Bogotá en las primeras décadas del siglo XX y se mantiene aún vigente en la localidad de San Cristóbal. De manera paralela a este proceso, surgen formas particulares de ver la vida, desde una mirada festiva, como formas de resistencia local en su reinterpretación territorial. El mundo obrero se asocia en la localidad de San Cristóbal en el suroriente de Bogotá con el trabajo artesanal que se ve en estas fotos de los talleres de oficios: Zapateros, sastres, tipógrafos, trabajadores de chircales y fábricas de materiales de inicios del siglo XX.

El trabajo obrero de principios del siglo en los chircales, explotaba arcilla, tejas, ladrillos que se elaboraban en pequeñas fábricas como: Fabrica de Tubos de Gres “El Vencedor”, Tubos Moore y la Caja de Vivienda Popular. En América Latina, el movimiento obrero ha sido uno de los actores permanentes del escenario de conflictividad social dados los procesos de industrialización de inicios del siglo XX.

El suroriente en Bogotá, atrajo a principios del siglo XX grandes poblaciones obreras que se asentaron en los barrios que se fueron construyendo a partir de las fábricas y de la compra de terrenos para construir urbanizaciones de carácter popular; fueron escenarios en donde se conformó la clase obrera desde las primeras décadas del siglo XX, en relación con la construcción inmobiliaria y de vías que, con la construcción del tranvía en 1938, ampliarían su influencia e impacto. En Colombia en 1931 se reconoció el derecho de asociación sindical, el establecimiento de ocho horas, reglamentada a través del Decreto 895 (26 de abril de 1934), "el buen uso" del tiempo libre de los obreros se planteó como una preocupación común de los empresarios, el Gobierno y el clero, pues se trataba de evitar a toda costa que las "ideas revolucionarias" del sindicalismo socialista tuvieran influencia sobre los trabajadores, ante lo cual era preciso ejercer control social sobre estos sectores. (González; Molinares, 2013 Pág. 175) La creación de barrios obreros apuntaba a tener cerca de las fábricas a los trabajadores es el caso del barrio obrero de Villa Javier, para ejercer vigilancia y control frente a actividades sindicales y de resistencia al régimen laboral. El fundador del —Círculo de Obreros el 1 de enero de 1911, día que también se formaliza una caja de ahorros de los mismos obreros. Según palabras del propio sacerdote el Círculo de Obreros era: - Una sociedad - no política - que tiene por objeto atender el perfeccionamiento de la clase obrera en el orden económico, intelectual, moral y religioso (Hernández, 2020 Pág.84)

\section{ANÁLISIS DE CULTURAS DE OCIO EN AGRUPACIONES OBRERAS EN EL SURORIENTE DE BOGOTÁ}

Los tiempos de ocio en relación al mundo obrero del suroriente están relacionados a aquellos espacios en los cuales existen dos factores interrelacionados: la liturgia católica que entraban a reglamentar la vida cotidiana de los habitantes de los barrios en su tiempo libre y algunas culturas festivas que se configuran en la búsqueda de orígenes rurales, campesinos o de otras regiones del país con el paso de las décadas. Si bien existen culturas festivas que aluden a memorias locales de 
los lugares originarios de los migrantes, también existen para los principios del siglo XX nuevas culturas urbanas dedicadas al trabajo industrial y al trabajo artesanal propio del siglo XIX, que se va a enseñar en talleres de oficios herederos de una tradición previa, se incluyeron en la vida de los bogotanos algunas fiestas cívicas pero sin modificar los regocijos católicos propios del siglo anterior; actividades como los paseos a chapinero, al luna park, eran formas de ocio de los habitantes del suroriente. Ernesto González, en el año de 1917 se dio a la tarea de buscar un lugar de descanso y esparcimiento. González, al ver en la rivera del Río Fucha, varias zonas que se inundaban frecuentemente, encontraron el lugar perfecto para hacerlo, represó parte del río y adecuó dicho lugar para tener un majestuoso lago, invirtió en canoas, juegos mecánicos y arregló una isla en medio de aquel lago y lo llamo el Luna Park.

El parque ya tenía asegurado un gran público, y con la inauguración del ramal sur del tranvía, los visitantes desbordaban su capacidad. Ellos venían de todas las clases sociales, los pudientes e intelectuales se reunían en La Casita, un restaurante de alto gourmet que contaba con orquesta. Por otra parte, la gente humilde se reunía en La Rondinela, otro restaurante que hacía las veces de piqueteadero y donde un conjunto de cuerdas interpretaba su música al lado de una pista de tejo. (Nieves, 2016).

Este espacio perdido con el paso de las décadas y la creciente urbanización giro hacia nuevas prácticas menos relacionadas con la naturaleza. En la actualidad, la naturaleza se encuentra en la parte alta de la localidad de San Cristóbal, ya no en la parte baja que tiene pocos parques como espacios de ocios, de recreación dada la creciente urbanización de la localidad.

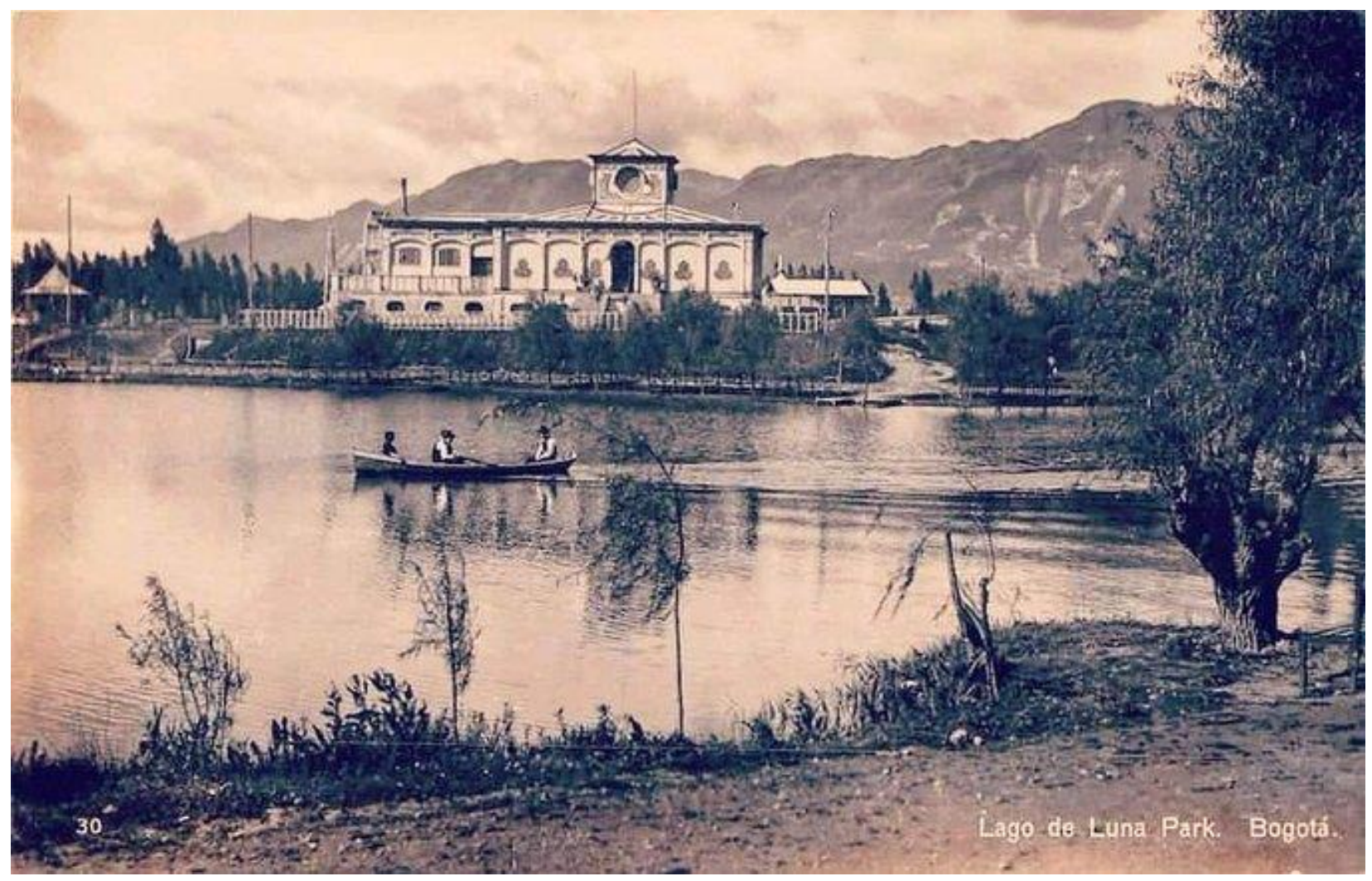

Fig. 1 Nieves, A (2016) Foto antigua, sin autor principios del siglo XX Lago Luna Park, San Cristóbal. 
Las prácticas de ocio de inicios del siglo XX, han dado giros de acuerdo al lugar y momento de producción. El salir de la ciudad al campo, es una práctica cultural que aún se realiza para el bogotano del común. Los espacios son construidos culturalmente. Si bien el lago Luna park no existe más, el recuerdo de un espacio público habitable se recuerda en la memoria colectiva de los habitantes de la localidad, en una habitación que en la actualidad se desplaza a la parte oriental en los cerros en el Parque Entre nubes en la parte alta de la localidad que viene siendo conservado por agrupaciones culturales que hacen actividades deportivas y de ocio.

La vida cotidiana del habitante de San Cristóbal a inicios del siglo XX, tenía una relación directa con la naturaleza que al paso de las décadas subsiguientes desapareció de manera muy rápida, los amplios bosques que rodeaban la parte baja de la localidad fueron talados en menos de dos décadas para dar paso a una urbanización que deforestó la localidad desde los años treinta a los años sesenta. Por otra parte, es un momento histórico en el cual se construyeron edificaciones con importancia patrimonial, en casas que se mantienen hoy en día, algunas han sido ya demolidas.

Algunas fábricas mantenían un estilo español en su construcción, realizadas en ladrillos cocidos realizados en el sector del suroriente, es el caso de la Fábrica de Tubos de Gres "El Vencedor" iniciada por Ana Julia Peñuela y Eduardo Caicedo industriales de 1920 a 1965, ya demolida, como se observa en la siguiente fotografía:

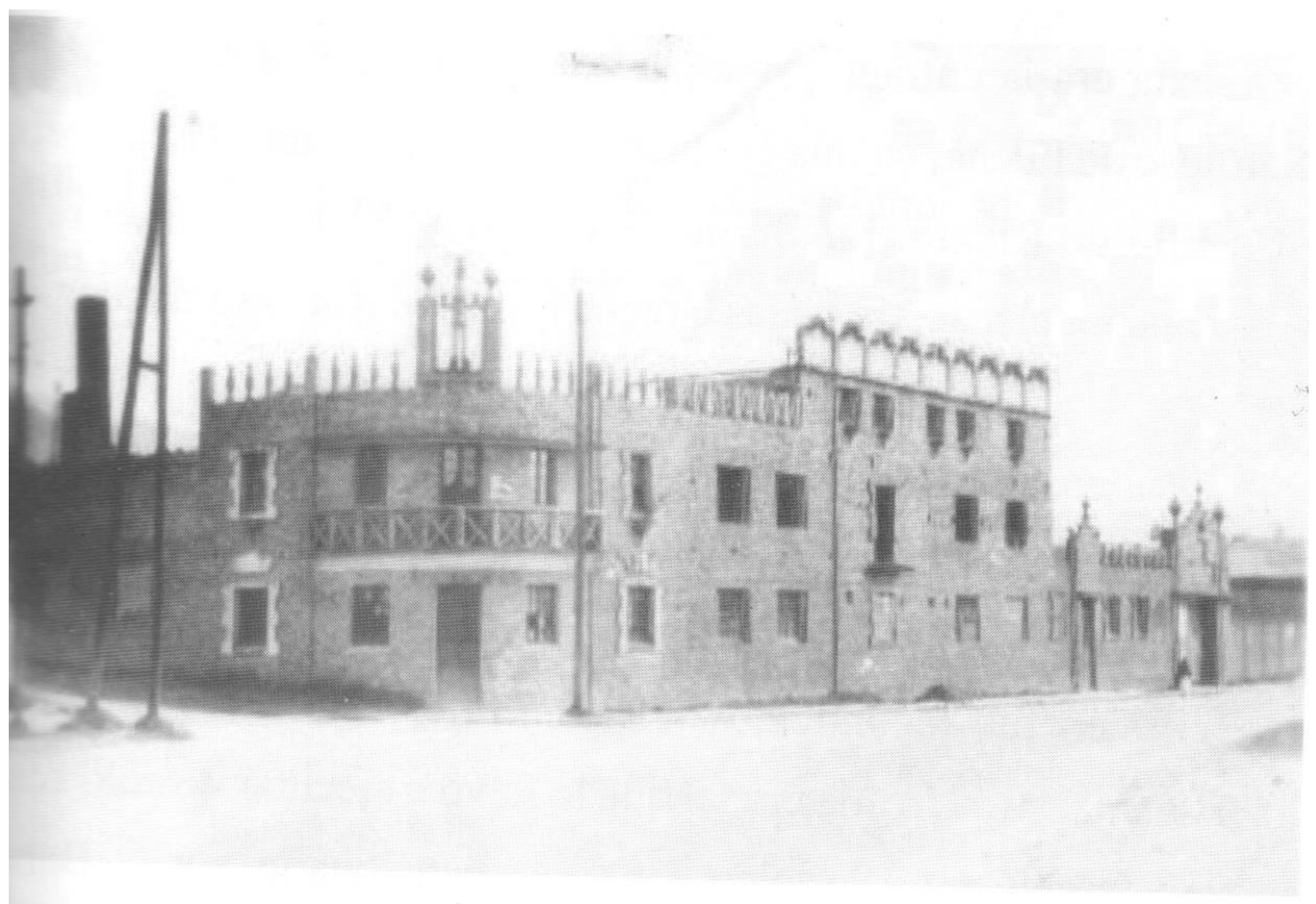

Fig. 2 Luna, D (2021) Fotografía Fábrica de Tubos de Gres "El Vencedor, Localidad de San Cristóbal de principios del siglo XX. Ubicada en la actual Calle 12 sur carrera 6 en Bogotá. 


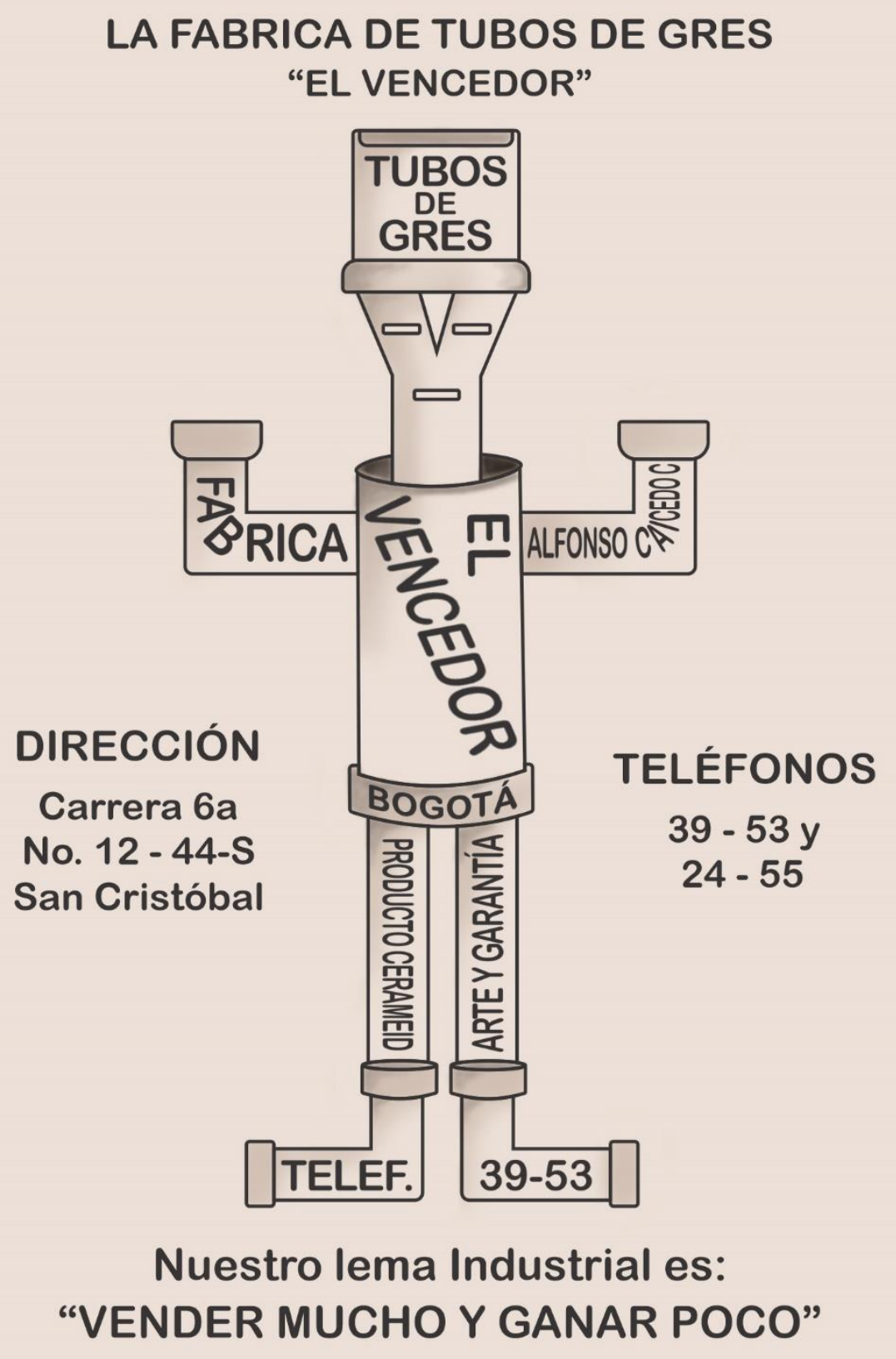

Fig. 3 Sin autor. Logotipo de la Fábrica de Tubos de Gres "El Vencedor, Localidad de San Cristóbal. un hombre realizado en tubos, mantiene la idea central de la industrialización como promesa de progreso, una nueva era que traía nuevas industrias y tecnologías. 


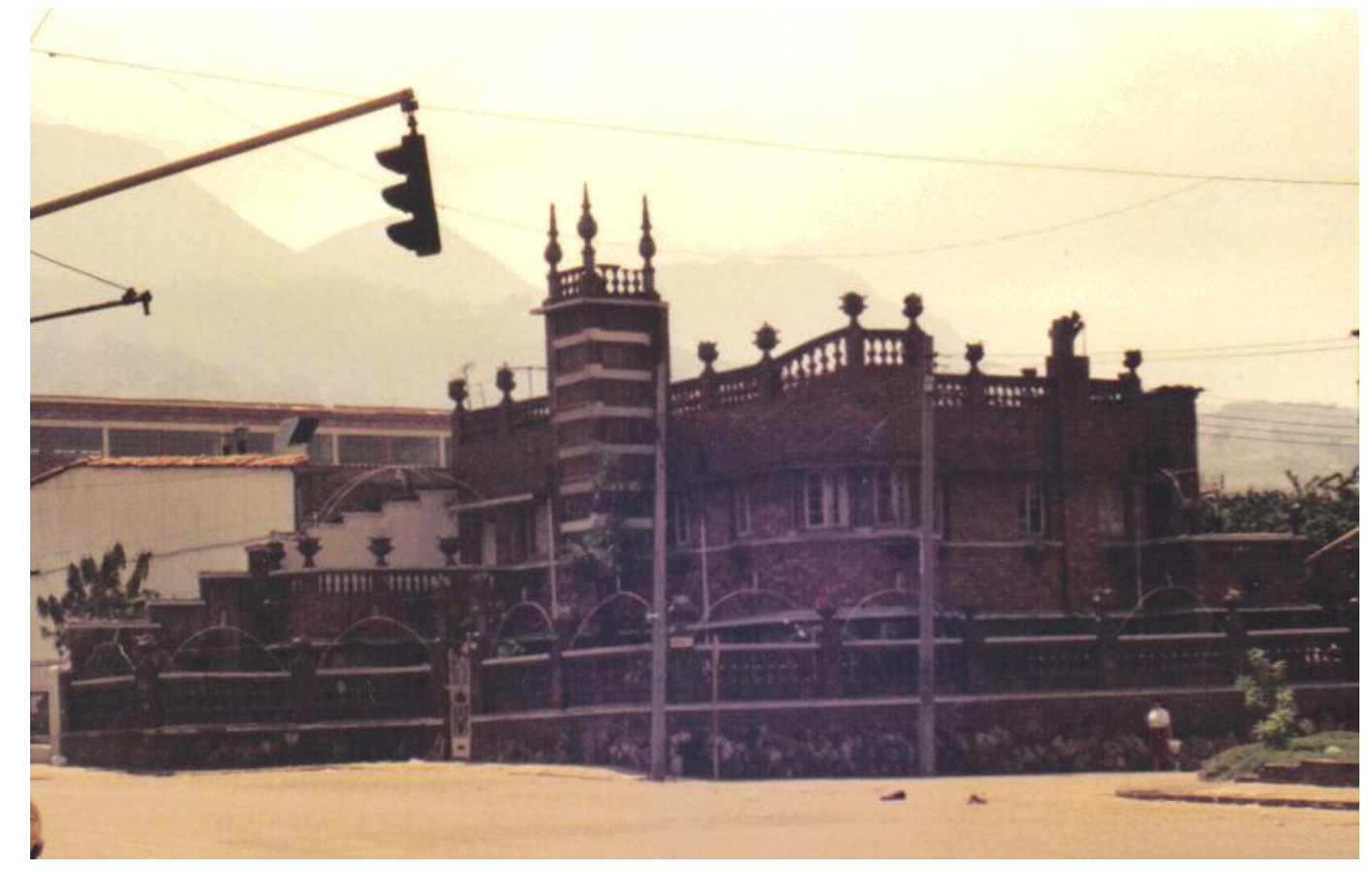

Fig. 4 Luna, D (2021) Fotografía de la casa quinta Villa Ana Julia, conocida como "El Castillo" construido por los mismos dueños de la Fábrica "EL Vencedor" en el año de 1920. En la actualidad su dueño el señor Daniel Luna busca su reconocimiento patrimonial para evitar su desaparición frente a una urbanización contemporánea que amenaza su conservación, al igual que disputas familiares que tienen puntos de vista encontrados frente al uso y futuro del inmueble.

En este mismo entorno se realiza arquitectura que presenta "un estilo ecléctico con aires de estilo republicano. Era la vivienda y oficina de la Fábrica de Tubos de gres "El vencedor" que fue premio nacional en ferias industriales de Bogotá "La gran Exposición de Bogotá 1931" producía los tubos de gres de mayor diámetro en Colombia. La fábrica estaba una cuadra al sur, en ese entonces, eran las afueras de la ciudad construida" (Hernández, 2020).

En este mismo sentido resulta útil realizar un mapeo de inmuebles patrimoniales de la localidad 4 con el fin de establecer procesos y tiempos de urbanización desde los inicios del siglo y ampliar posibles investigaciones a futuro en relación con prácticas culturales propias de este territorio.

\section{DISCUSIÓN}

En las discusiones sobre los orígenes y contexto social del mundo obrero, fue originado con prácticas artesanales propias de épocas anteriores, previas a la independencia, propias del mundo colonial que se mantuvieron vivas posteriormente al proceso independentista. Las prácticas artesanales fueron de nuevo incentivadas en procesos de educación y oficios propios de inicios del siglo XX, tanto taller de oficios de sastres, tipografías en imprentas locales, zapaterías, dieron pie a un proceso de trabajo obrero que se reprodujo en las incipientes fábricas de finales del siglo XIX y principios del siglo XX en un cambio hacia un capitalismo industrial que se fue instalando poco a poco cambiando también la configuración urbana de barrios con presencia de artesanos, para convertirse poco a poco en barrios con presencia de obreros. 


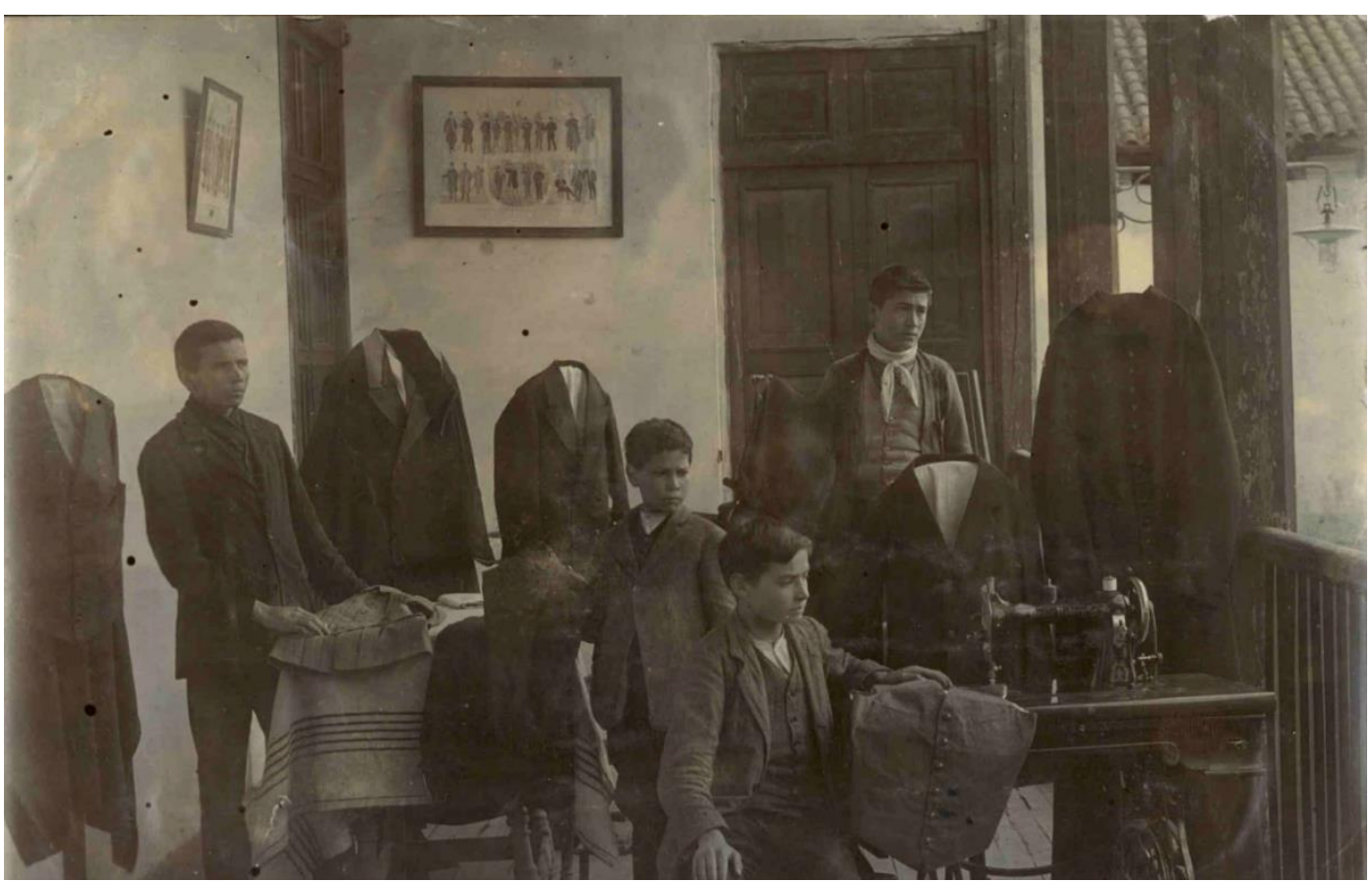

Fig. 5 Sin autor. Alumnos sastrería 1911. Fuente: Centro Histórico Salesiano Inspectoría

Para Mauricio Archila (1992), el mundo obrero construye una identidad de clase social desde su auto mirada del trabajo campesino a los cambios de poblaciones en su ingreso a la ciudad en un camino recorrido para llegar a la clase, "desde el campesinado y desde los rezagos del artesanado; la resistencia del obrero a la proletarización, tantas veces comprobada por la investigación social de nuestro medio; la vida cotidiana de las primeras generaciones de obreros; su empleo del tiempo libre; su "encuentro" con necesidad de la organización política independiente: todo contribuye a edificar tortuosa, tercamente, la identidad de la nueva clase social”. (Archila, 1992. Pág. 23).

Es importante establecer que si bien la discusión de la identidad de clase que tienen los obreros en su vida cotidiana consiste en un proceso social de décadas, también la influencia de esta reciente clase social por diversos actores culturales se vuelve un factor importante que ha llevado a autores diversos a reflexionar sobre el impacto social de la iglesia católica en las costumbres y vida cotidiana de los habitantes de las ciudades (Obreros, artesanos, campesinos). En las imágenes de los Talleres salesianos de inicios del siglo XX, se observan formas de habitar un espacio socialmente construido. El estudio sobre las maneras de habitar la ciudad pretende dilucidar las prácticas culturales de los usuarios de la ciudad en el espacio de su barrio como punto de partida, lógico si no cronológico (De Certeau, 1999 Pág. 5). Es entonces una de alas discusiones más importantes la relación entre lo cotidiano como forma de habitar un lugar y las actividades que se desarrollan en un espacio que entra en la definición de lo "artesanal" y se transforma hacia la definición del mundo "obrero" que se construye en una definición territorial pequeña, llamada el barrio. Existen constantes indicaciones sobre las dimensiones que definen un barrio, sus características históricas, estéticas, topográficas, socio profesionales. Para Henri Lefebvre, el barrio es "una puerta de entrada y salida entre los espacios calificados y eI espacio cuantificado". El barrio aparece como el dominio en el cual la relación espacio/tiempo es la más favorable para un qué se transforma a partir de su hábitat. 


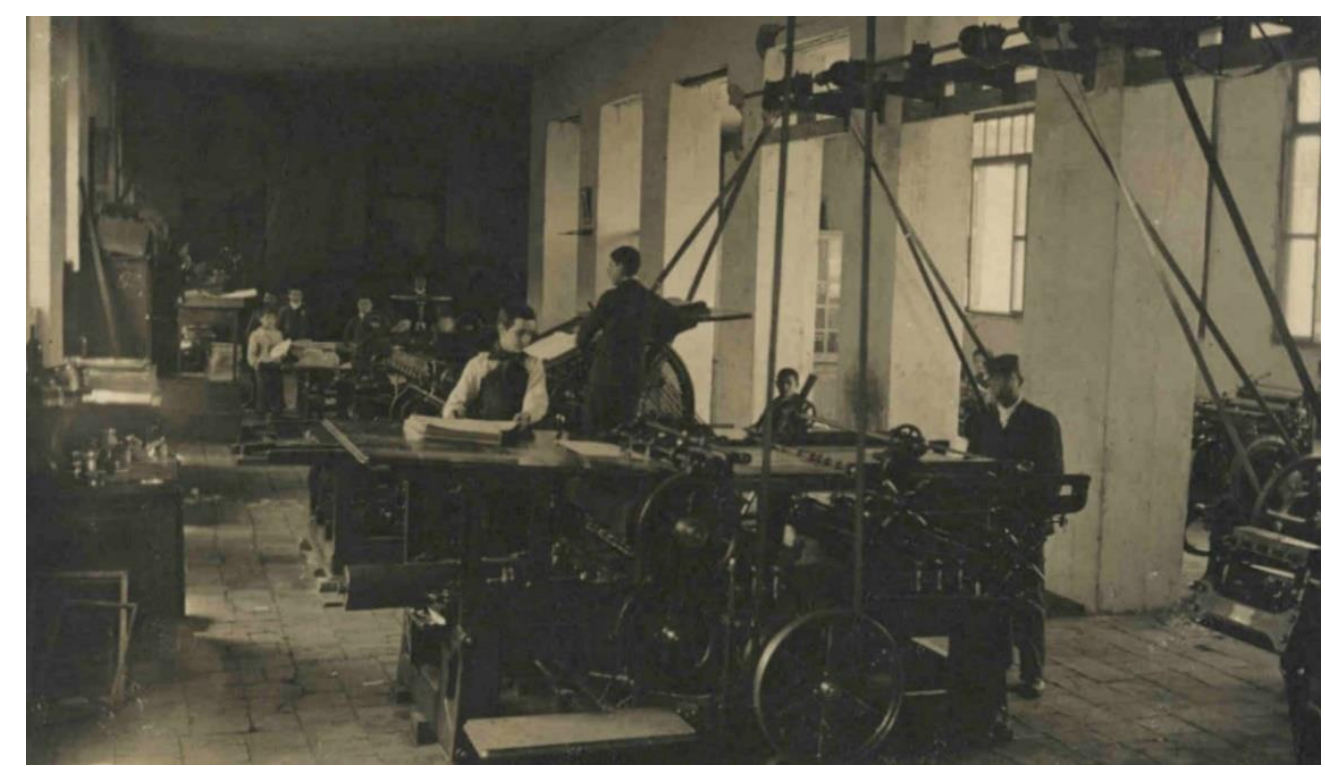

Fig. 6 Sin autor. Tipografía, artes gráficas 1911. Fuente: Centro Histórico Salesiano Inspectoría

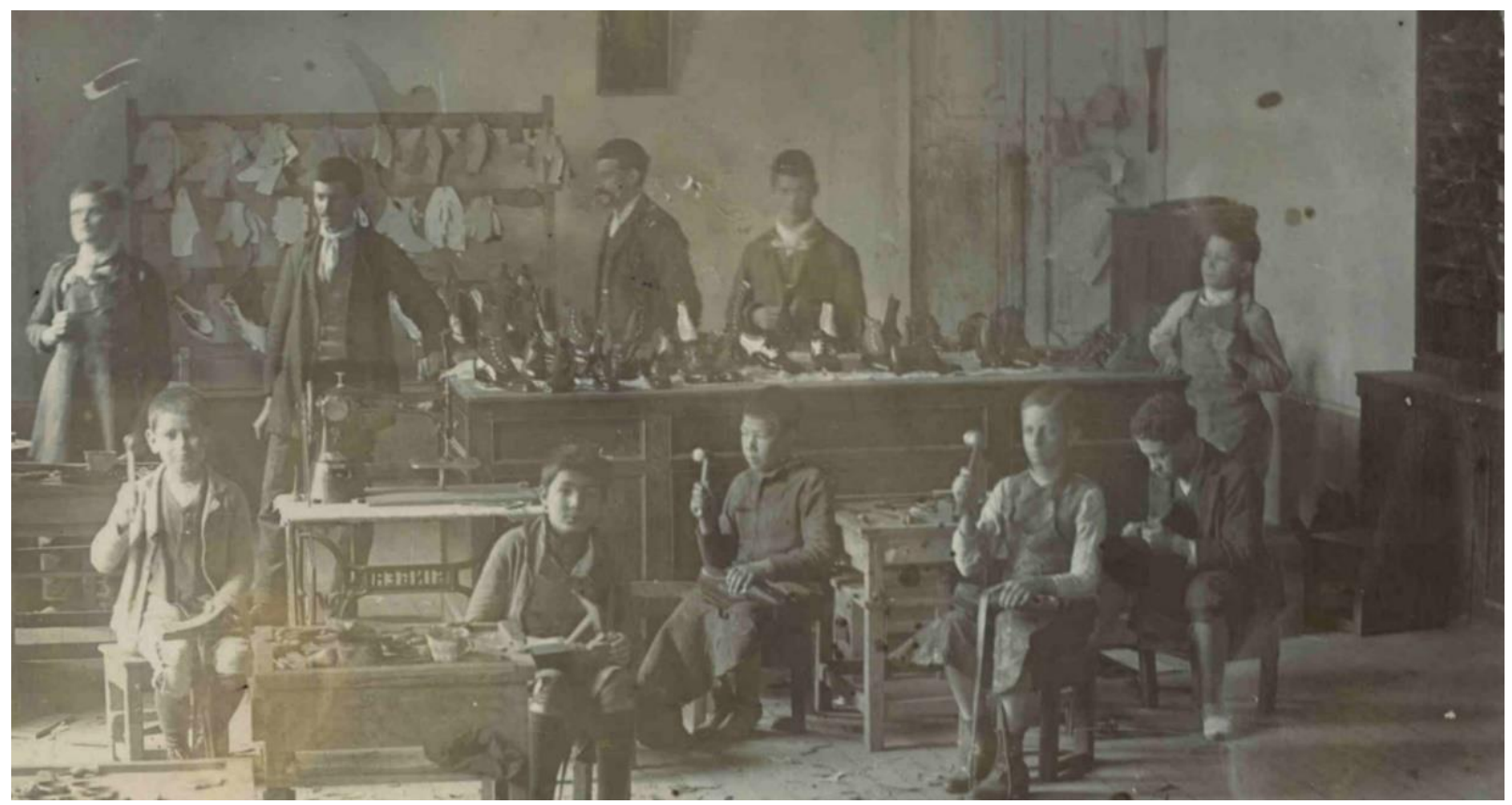

Fig. 7 Sin autor. Taller de Zapatería. 1910. Centro Histórico Salesiano Inspectoría

\section{CONCLUSIONES}

Las sociedades obreras del suroriente a principios del siglo $\mathrm{XX}$, cuentan con afectividades que configuran culturas comunitarias con sentidos de apropiación territorial. Fernández Christlieb (2000) plantea la noción de afectividad y puede aplicarse a comunidades obreras del suroriente, frente a su situación de vulnerabilidad, presentan vínculos comunitarios, que crean nuevas relaciones y tejidos sociales que construyen espacios de sociabilidad en donde la forma de vida urbana relacionada con los oficios y artesanos, convivieron en entornos relativamente pequeños y 
cerrados en los barrios que a su vez por medio de regulaciones sociales.

El espacio social y cultural de inicios del siglo XX, crea espacios urbanos, en los cuales la calle era un gran espacio social. Las emociones, la sexualidad, la solidaridad, los antagonismos, las distinciones sociales de noche, cuando los mayores salían con las sillas a conversar y tomar el fresco, nosotros lo aprovechábamos para ir más allá, correr, perseguirnos, jugar (p.10).

De Certeau, Giard y Mayol (1999) mencionan que las prácticas sociales se dan gracias a la gratuidad y no tanto a la necesidad, es decir, el espacio social no está relegado solamente a un uso funcional, sino que es, además, el espacio de un reconocimiento de lo común que únicamente puede sostenerse gracias a la convivencia cultural que configura un espacio comunitario. De hecho, la vida obrera homogénea en sus relaciones laborales impone de cierta manera en las primeras fabricas de la ciudad un estilo de relaciones en las cuales las comunidades obreras comparten afectos, espacios, problemáticas, experiencias de vida y cotidianidades que son comunes entre todos.

La incipiente industrialización en la ciudad de Bogotá, crea entornos cercados de vida cotidiana, no solamente en experiencias o afectividades en común, sino también en la urbanización de vida en sus usos y costumbres. La arquitectura fue para este momento un instrumento de la división social de clase; Grandes edificios que mantenían industrias con un ánimo moderno, mostraban el ánimo de progreso frente a urbanizaciones pobres de artesanos y obreros, que, si acaso tenían acceso a una vivienda, en algunas industrias como por ejemplo la cervecera, Bavaria su dueño incentivó la creación de barrios obreros cercanos a la industria, es el caso de Leo Siegfried Kopp.

\section{REFERENCIAS}

Archila, M (1992) Cultura e identidad obrera, Colombia 1910-1945 Ed. Cinep, Bogotá, Col

De Certeau, M.; Giard, L. y Mayol, P. (1999). La invención de lo cotidiano 2: habitar, cocinar. México: Universidad Iberoamericana, Instituto Tecnológico y de Estudios Superiores de Occidente

Galindo, C. y Delgado, J. (2006). Los espacios emergentes de la dinámica rural-urbana. Problemas del Desarrollo, 37 (147).

Crouse M. 2001. Citing Electronic Information in History Papers. Disponible en: http:/www.people.mephis.edu/mcrouse/elcite.html.

Hernández, R (2020) Urbanizando San Cristóbal y Santa Ana // Desde la Quinta "La Milagrosa". Ed. Arquitectura Editorial Rubén Hernández Molina. Bogotá, Colombia. 192 págs.

Herrera, C (2018) La producción del espacio comunitario. Habitar el suroriente bogotano. Ed. Pontificia Universidad Javeriana. Bogotá

Monguí, A. (2010) San Cristóbal habla "Fucha”. Alcaldía Mayor de Bogotá, Bogotá, Col. 
Nieves, A (2016) Siete ecosistemas bogotanos arrasados por la urbanización En: https://humedalesbogota.com/2016/08/24/siete-ecosistemas-bogotanos-arrasados-laurbanizacion/

\section{SEMBLANZA DE LA AUTORA}

Liliana Cortés Garzón: Historiadora Magister en Arte y Ph. D en Arte de la Universidad Autónoma de Barcelona. Es investigadora activa y directora del Proyecto SUR plataforma de investigaciones en prácticas artísticas, urbanas y culturales de regiones del Sur del planeta. Trabaja en líneas de investigación vinculadas con las artes, las prácticas culturales en entornos urbanos y rurales en regiones fronterizas. Ha sido docente universitaria y gestora cultural en Colombia, España y Turquía. 